\title{
Comparação do Desempenho Operacional e das Características do Cordão na Soldagem com Diferentes Arames Tubulares em Polaridade Negativa
}

\section{(Comparison of Operational Performance and Bead Characteristics when Welding with Different Tubular Wires in Negative Polarity)}

\author{
Cícero Murta Diniz Starling ${ }^{1 *}$, Paulo José Modenesi², Tadeu Messias Donizete Borba ${ }^{3}$ \\ ${ }^{1}$ Universidade Federal de Minas Gerais, Departamento de Engenharia de Materiais e Construção, Belo Horizonte, Minas Gerais, \\ Brasil, cicerostarling@ufmg.br \\ ${ }^{2}$ Universidade Federal de Minas Gerais, Departamento de Engenharia Metalúrgica e de Materiais, Belo Horizonte, Minas Gerais, \\ Brasil, modenesi@demet.ufmg.br \\ ${ }^{3}$ Universidade Federal de Minas Gerais, Engenheiro Metalurgista, Belo Horizonte, Minas Gerais, Brasil,tadeumdborba@yahoo.com.br \\ *Autor para quem toda a correspondência deve ser encaminhada
}

\section{Resumo}

Este trabalho objetivou o estudo comparativo das características do cordão produzido por arames tubulares nacionais dos tipos rutílico (ASME SFA-5.20: E71T-1/E71T-9/E71T-9M), básico (ASME SFA-5.20: E71T-5/E71T-5M) e "metal cored" (ASME SFA-5.18: E70C$3 M)$ com 1,2 mm, destinados à soldagem de aços estruturais de baixo e médio teor de carbono. Realizaram-se testes de soldagem com o eletrodo na polaridade negativa (CC-), na posição plana, sobre chapas grossas (espessura de $12 \mathrm{~mm}$ ) de aço carbono comum de baixo carbono utilizando-se uma fonte operando no modo "tensão constante" e com monitoração dos sinais de corrente e tensão do arco e velocidade de alimentação (fusão) do arame. Variaram-se, na soldagem com cada tipo de arame tubular, a composição do gás de proteção $\left(75 \% \mathrm{Ar}-25 \% \mathrm{CO}_{2}\right.$ e $\left.100 \% \mathrm{CO}_{2}\right)$ e a velocidade de alimentação do arame $(7$ e $9 \mathrm{~m} / \mathrm{min})$. Os demais parâmetros foram mantidos fixos, incluindo-se, além da polaridade negativa do eletrodo, os comprimentos energizado do eletrodo (16 mm) e do arco $(3,5 \mathrm{~mm})$. Para os diferentes arames tubulares, avaliaram-se comparativamente as principais características do cordão, incluindo a sua geometria (penetração, reforço, largura, área fundida, área depositada e diluição), presença de descontinuidades, microestrutura e dureza. Levantaram-se as condições operacionais associadas a um cordão com características adequadas à soldagem de chapas grossas de aços estruturais com a polaridade do eletrodo negativa.

Palavras-chave: Processo FCAW; Arame Tubular; Formato do Cordão; Microestrutura; Polaridade Negativa.

Abstract: This paper compares the bead characteristics of welds deposited of carbon steel tubular wires. Three tubular wires of $1.2 \mathrm{~mm}$ produced in Brazil were used: rutilic (ASME SFA-5.20: E71T-1/E71T-9/E71T-9M), basic (ASME SFA-5.20: E71T-5/E7IT-5M) and metal cored (ASME SFA-5.18: E70C-3M). Welding trials were performed in downhand position on thick (12 mm) low-carbon steel plates using a constant voltage power supply in negative wire polarity (CC-). Welding current and voltage, and wire feed rate were monitored in all trials. For each tubular wire type, the shielding gas composition $\left(75 \% \mathrm{Ar}-25 \% \mathrm{CO}_{2}\right.$ and $\left.100 \% \mathrm{CO}_{2}\right)$ and wire feed rate (7 and $9 \mathrm{~m} / \mathrm{min}$ ) were changed, and other process variables, including electrode and arc lengths (16 $\mathrm{mm}$ and $3.5 \mathrm{~mm}$, respectively) were kept constant throughout the experimental program. Weld bead geometry parameters (penetration depth, reinforcement, width, fused and deposited areas, and weld dilution), presence of weld discontinuities, fusion zone microstructure and hardness were measured and compared for the different tubular wires. Operational conditions that yielded weld bead characteristics favored for the welding of thick plates of structural steels on negative wire polarity were determined.

Key-words: FCAW Process; Tubular Wire; Weld Bead Shape; Microstructure; Negative Polarity.

\section{Introdução}

A soldagem a arco com arame tubular (FCAW) é um processo que acumula as principais vantagens da soldagem com arame maciço e proteção gasosa (GMAW), como alto fator de

(Recebido em 28/07/2011; Texto final em 05/12/2011).

Artigo originalmente publicado no COBEF trabalho do soldador, alta taxa de deposição, alto rendimento, resultando em alta produtividade e qualidade da solda produzida. Inclui também as vantagens da soldagem manual com eletrodos revestidos (SMAW), como alta versatilidade, possibilidade de ajustes da composição química do cordão de solda e facilidade de operação em campo[1-2]. Na soldagem FCAW e em outros processos de soldagem com eletrodo consumível, o material do eletrodo precisa ser aquecido desde a sua temperatura inicial, próxima da temperatura ambiente, até a sua temperatura de fusão e, a seguir, ser fundido e separado do eletrodo. A velocidade com 
que o eletrodo é fundido deve ser, em média, igual à velocidade que este é alimentado de forma a manter um comprimento de arco relativamente constante.

Em trabalhos anteriores [3-7], os autores do presente trabalho estudaram as características e os fatores determinantes da fusão e da transferência metálica de arames tubulares nacionais (destinados à soldagem de aços carbono comuns de baixo e médio teor de carbono) dos tipos básico (ASME SFA-5.20: E71T-5/E71T-5M), rutílico (ASME SFA-5.20: E71T-1/E71T-9/ E71T-9M) e "metal cored" (ASME SFA-5.18: E70C-3M) com $1,2 \mathrm{~mm}$ diâmetro, utilizando uma fonte do tipo "tensão constante" e condições de soldagem com ausência ou pequena ocorrência de curtos-circuitos. Esses aspectos, até então estudados, foram muito importantes, tendo aplicação na determinação de condições operacionais de maior produtividade, no controle do processo e no projeto de juntas soldadas.

Encontrou-se na literatura alguns estudos relativos às características do cordão de solda (por exemplo, geometria, presença de descontinuidades e microestrutura) na soldagem com arames tubulares[8-15]. De uma forma geral, estes estudos associam as características do cordão com os parâmetros de soldagem ou com as propriedades mecânicas da junta soldada. Entretanto, percebe-se que os aspectos relativos às características do cordão de solda no processo FCAW não foram, ainda, estudados de forma mais abrangente, por exemplo, associando estas características às condições operacionais para aplicações envolvendo arames tubulares destinados à soldagem de aços carbono comuns de baixo e médio teor de carbono. Dessa forma, informações relativas às condições operacionais associadas a um cordão com características adequadas à soldagem de aços estruturais são, até então, limitadas.

Da mesma forma que o estudo das características e dos fatores determinantes da fusão de arames tubulares, um estudo exploratório, realizado para arames tubulares nacionais destinados à soldagem de aços carbono comuns de baixo e médio teor de carbono, sobre o efeito das condições operacionais nas características do cordão de solda (por exemplo, geometria, presença de descontinuidades e microestrutura) revela-se igualmente importante. Em estudos anteriores, os autores do presente trabalho avaliaram os efeitos da velocidade de alimentação do arame, do gás de proteção e da polaridade do eletrodo nas características do cordão produzido por arames tubulares nacionais dos tipos básico (ASME SFA-5.20: E71T5/E71T-5M)[16], rutílico (ASME SFA-5.20: E71T-1/E71T-9/ E71T-9M)[17] e "metal cored" (ASME SFA-5.18: E70C-3M) [18]. Os autores também realizaram um estudo comparativo das características operacionais do processo e do cordão resultantes dos mesmos tipos de arames tubulares na soldagem com polaridade positiva, controlando-se a velocidade de alimentação do arame e o tipo de gás de proteção[19] e, no presente trabalho, será realizado um estado comparativo similar na soldagem com polaridade negativa. Espera-se que esses novos resultados gerados para os referidos arames tubulares possam contribuir para a otimização de condições operacionais associadas a um cordão de solda com características adequadas à soldagem de aços estruturais e, também, possam resultar em uma importante contribuição dado o número limitado de informações relativas à soldagem de arames tubulares com polaridade negativa.

\section{Materiais e Métodos}

Neste trabalho, utilizou-se o processo FCAW com arames tubulares comerciais de fabricação nacional (destinados à soldagem de aços carbono comuns de baixo e médio teor de carbono) dos tipos básico (ASME SFA-5.20: E71T-5/E71T-5M), rutílico (ASME SFA-5.20: E71T-1/E71T-9/E71T-9M) e "metal cored" (ASME SFA-5.18: E70C-3M), possuindo diâmetro nominal de $1,2 \mathrm{~mm}$. Os testes de soldagem foram realizados na posição plana sobre chapas de aço carbono comum (ABNT 1010, com 50x250x12 mm) utilizando-se uma fonte de soldagem operando no modo "tensão constante" com a polaridade do eletrodo negativa (direta, CC-). Para cada tipo de arame tubular, objetivando avaliar o efeito das principais condições operacionais nas características do cordão de solda, variou-se a velocidade de alimentação (fusão) do arame (7 e $9 \mathrm{~m} / \mathrm{min}$ ) e o gás de proteção $\left(75 \% \mathrm{Ar}-25 \% \mathrm{CO}_{2}\right.$ e $\left.100 \% \mathrm{CO}_{2}\right)$, totalizando 12 condições distintas avaliadas (Tabela 1). Realizaram-se duas soldas para cada condição avaliada e, dependendo da variabilidade dos resultados, réplicas adicionais.

No início de cada teste, o valor desejado da velocidade de alimentação do arame era ajustado e, em seguida, promovia-se o ajuste do comprimento do arco $(3,5 \mathrm{~mm}$, medido através de um sistema de projeção da sua imagem) pela variação da tensão fornecida pela fonte de soldagem. Previamente, a distância entre a peça e o bico de contato era fixada em 19,5 mm resultando, após o ajuste do comprimento do arco, em um comprimento energizado do eletrodo igual a $16,0 \mathrm{~mm}$. De forma a se manter aproximadamente constante o volume da poça de fusão e, assim, tornar sistemática a sua influência no ajuste do comprimento do arco, foi estabelecida uma relação de proporcionalidade entre as velocidades de soldagem $\left(\mathrm{v}_{\mathrm{s}}\right)$ e de alimentação do arame (w), sendo a primeira mantida 25 vezes menor do que a segunda. Após estes ajustes, os valores resultantes de corrente de soldagem, tensão do arco (avaliada entre o bico de contato e a peça) e velocidade de alimentação do arame eram coletados através de placas de aquisição de dados acopladas a microcomputadores. Para a aquisição da corrente, utilizou-se um sensor de efeito Hall e, para a aquisição da tensão, um sensor divisor de tensão, ambos ligados a uma placa de conversão analógico/digital controlada por um programa de computador desenvolvido previamente. Para a aquisição da velocidade de alimentação do arame, utilizou-se um sensor de disco óptico ligado a uma placa de aquisição de dados, controlada por um programa de computador específico.

A caracterização de cada condição operacional avaliada foi realizada através da avaliação da estabilidade operacional, do aspecto superficial do cordão de solda, da taxa de deposição e, também, extraindo-se corpos de prova transversais ao cordão para análises macroestrutural e microestrutural e para realização de testes de dureza Vickers. 
Tabela 1. Condições operacionais avaliadas na soldagem com diferentes arames tubulares em polaridade negativa. $\mathrm{w}-$ velocidade de alimentação nominal do arame.

\begin{tabular}{|c|c|c|}
\hline $\begin{array}{l}\text { Arame } \\
\text { Tubular }\end{array}$ & $\begin{array}{c}\text { Gás } \\
\text { Proteção }\end{array}$ & $\begin{array}{c}\mathrm{W} \\
(\mathrm{m} / \mathrm{min})\end{array}$ \\
\hline \multirow{4}{*}{ Rutílico } & \multirow{2}{*}{$75 \% \mathrm{Ar}-25 \% \mathrm{CO}_{2}$} & 7 \\
\hline & & 9 \\
\hline & \multirow{2}{*}{$100 \% \mathrm{CO}_{2}$} & 7 \\
\hline & & 9 \\
\hline \multirow{4}{*}{ Básico } & \multirow{2}{*}{$75 \% \mathrm{Ar}-25 \% \mathrm{CO}_{2}$} & 7 \\
\hline & & 9 \\
\hline & \multirow{2}{*}{$100 \% \mathrm{CO}_{2}$} & 7 \\
\hline & & 9 \\
\hline \multirow{4}{*}{ "Metal Cored" } & \multirow{2}{*}{$75 \% \mathrm{Ar}-25 \% \mathrm{CO}_{2}$} & 7 \\
\hline & & 9 \\
\hline & \multirow{2}{*}{$100 \% \mathrm{CO}_{2}$} & 7 \\
\hline & & 9 \\
\hline
\end{tabular}

A estabilidade operacional de cada uma das condições testadas foi avaliada através das análises dos oscilogramas de tensão do arco e corrente de soldagem, em particular da relação entre o desvio padrão e a média destes parâmetros, que indicam os seus níveis de flutuação durante a operação de soldagem. A estabilidade operacional foi avaliada adicionalmente pelo aspecto superficial do cordão, pelo nível de respingos produzidos e pela eficiência de deposição, em função de uma correlação mais direta desses fatores com a operação de soldagem, apesar dos mesmos estarem associados aos níveis de flutuação dos valores da tensão do arco e da corrente de soldagem.

Para a obtenção da eficiência de deposição $\left(\varphi_{\text {tubular }}\right)$ dos arames tubulares, inicialmente promovia-se a determinação da massa de uma chapa limpa e esmerilhada e, em seguida, depositava-se na mesma um cordão de solda utilizando-se uma das condições operacionais avaliadas. Após a soldagem, removia-se (com escova de aço giratória e talhadeira) todos os óxidos e respingos formados e determinava-se o ganho de massa do corpo de prova devido ao metal depositado. O consumo de arame (em metros) para a deposição do cordão era avaliado a partir da monitoração, durante a soldagem, da velocidade de alimentação do arame. Com o conhecimento da densidade linear dos arames tubulares rutílico $(6,93 \mathrm{~g} / \mathrm{m})$, básico $(6,95 \mathrm{~g} / \mathrm{m})$ e "metal cored" $(8,05 \mathrm{~g} / \mathrm{m})$, calculadas conforme procedimento descrito por Starling e Modenesi[3], era possível determinar a massa total de arame fundido durante a soldagem. Dessa forma, a eficiência de deposição era avaliada através da relação entre o ganho de massa do corpo de prova e a massa total de arame fundido. Para cada condição operacional, avaliou-se a eficiência de deposição média realizando-se pelo menos 2 soldas. A taxa de deposição ( $\mathrm{TD}_{\text {tubular }}$ ) dos arames tubulares depende da eficiência de deposição $\left(\varphi_{\text {tubular }}\right)$ e da velocidade de alimentação (w), Equação 1:

$$
\mathrm{TD}_{\text {tubular }}=0,06 \cdot \varphi_{\text {tubular }} \cdot\left(\mathrm{A}_{\text {tubular }} \cdot \rho_{\text {tubular }} \cdot \mathrm{W}\right)
$$

para $\mathrm{TD}_{\text {tubular }}(\mathrm{kg} / \mathrm{h})$ e $\mathrm{w}(\mathrm{m} / \mathrm{min})$. Nesta equação, $\mathrm{A}_{\text {tubular }}$ se refere à área total da seção transversal do arame rutílico $\left(1,0679 \mathrm{~mm}^{2}\right)$, básico $\left(1,0520 \mathrm{~mm}^{2}\right)$ ou "metal cored" $\left(1,0740 \mathrm{~mm}^{2}\right)$. Ainda, $\rho_{\text {tubular }}$ se refere à densidade volumétrica do arame rutílico $\left(6,48 \mathrm{~g} / \mathrm{cm}^{3}\right)$, básico $\left(6,61 \mathrm{~g} / \mathrm{cm}^{3}\right)$ ou "metal cored" $\left(7,50 \mathrm{~g} / \mathrm{cm}^{3}\right)$. Tanto $A_{\text {tubular }}$ como $\rho_{\text {tubular }}$ foram calculadas conforme procedimento descrito por Starling e Modenesi[3].

Prepararam-se 2 macrografias e 1 micrografia para cada uma das 12 condições distintas avaliadas. A preparação macrográfica foi realizada em dois corpos de prova transversais a um mesmo cordão e consistiu no lixamento com lixas d'água (granulometrias iguais a 100, 240, 320, 400, 600 e 1000), seguindo-se ataque com nital $10 \%$. A preparação micrográfica foi realizada em um único corpo de prova transversal ao cordão e consistiu no seu embutimento a quente com resina termofixa (baquelite), lixamento com lixas d'água (mesmas granulometrias anteriores), polimento com pastas de diamante (com granulometria de 9, 3 e $1 \mu \mathrm{m}$ ) e ataque com nital $2 \%$. Após a preparação das amostras, foram realizadas macrofotografias e microfotografias digitais da seção transversal do cordão. $\mathrm{O}$ aspecto superficial do cordão também foi documentado através de macrofotografia digital.

A partir das macrografias produzidas e, também, através do exame do aspecto superficial do cordão foi verificada a presença de eventuais descontinuidades (por exemplo, aspecto irregular do cordão, porosidades, mordeduras e inclusão de escória). As macrofotografias foram observadas em um projetor de perfil para a identificação dos contornos da zona fundida e medição de alguns parâmetros geométricos (largura, penetração máxima e reforço) e, com o auxílio de um programa de computador, determinação de parâmetros complementares (áreas depositada e de penetração e diluição), ilustrados na Figura 1. Os testes de dureza Vickers foram realizados na zona fundida de cada uma das 12 condições operacionais avaliadas. Utilizou-se uma carga de 98,1 N (10 kgf) com 10 a 15 medidas para cada condição e apresentaram-se os resultados para um intervalo de confiança de $95 \%$.

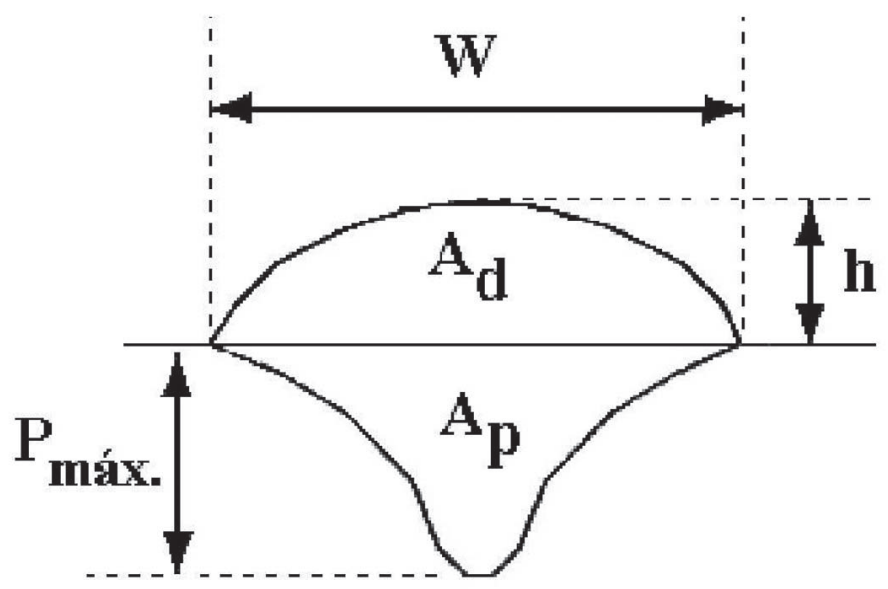

Figura 1. Representação esquemática das características geométricas do cordão. W - largura, h - reforço,

$\mathrm{P}_{\max }$-penetração máxima, $\mathrm{A}_{\mathrm{d}}$ - área depositada e $\mathrm{A}_{\mathrm{p}}$ - área de penetração. 
A caracterização microestrutural foi realizada através de exames ao microscópio óptico na seção transversal dos cordões para a identificação geral dos microconstituintes presentes na zona fundida. Também foram determinadas as frações volumétricas dos microconstituintes por metalografia quantitativa. A identificação dos microconstituintes foi baseada no documento IX-1533-88 do IIW - Instituto Internacional de Soldagem[20]. As frações volumétricas dos microconstituintes foram medidas pelo método de contagem manual de pontos, segundo a norma ASTM E 562-89[21].

Utilizou-se uma malha de 25 pontos a qual foi colocada na tela de um monitor de alta resolução acoplado a um microscópio óptico. As contagens foram realizadas para um aumento fixo de 500 X (arames rutílico e básico, em função de uma microestrutura mais refinada) ou 200 X (arame "metal cored", em função de uma microestrutura mais grosseira) no microscópio, o qual resultava em um aumento de, respectivamente, 1.200 ou $480 \mathrm{X}$ no monitor. Calculou-se um intervalo de confiança de $95 \%$ para os valores da fração volumétrica de cada microconstituinte. Para cada amostra, foram realizadas 100 aplicações da malha de forma a cobrir todas as regiões da zona fundida. Resultou-se, assim, na contagem de 2.500 pontos por amostra e, considerando-se as 12 condições distintas avaliadas, 30.000 pontos no total.

\section{Resultados e Discussão}

A Figura 2 mostra alguns exemplos de oscilogramas de corrente de soldagem e tensão do arco obtidos para as soldas com os arames tubulares. Nas legendas são indicados a média e o desvio padrão dos valores coletados da velocidade de alimentação do arame (w), da corrente de soldagem (I) e da tensão do arco (V) e, entre parênteses, a flutuação dos valores de corrente e tensão (relação entre o desvio padrão e a média correspondente). A Figura 3 mostra alguns exemplos do aspecto superficial dos cordões e das macrografias e micrografias obtidas. Apesar de todos os resultados das 12 condições operacionais avaliadas não terem sido apresentados nessas figuras, serão considerados na discussão dos resultados.

A Tabela 2 indica, para as condições operacionais avaliadas, os valores da energia de soldagem, eficiência de deposição, taxa de deposição e dureza na zona fundida das soldas. A Tabela 3 mostra os parâmetros geométricos e a diluição obtidos para os cordões de solda. A Tabela 4 indica a fração volumétrica dos microconstituintes presentes na zona fundida. A seguir são apresentados e discutidos os resultados mais relevantes oriundos das condições operacionais avaliadas.

\subsection{Avaliação Comparativa da Corrente e da Tensão do Arco}

Lesnewish[22] mostrou que, no processo GMAW, a fusão do eletrodo é controlada principalmente pelo calor transferido do arco para a ponta do eletrodo e pelo calor gerado por efeito Joule ao longo do eletrodo e propôs a seguinte equação empírica para a taxa de fusão de arame, Equação 2:

$$
w=\alpha I+\beta s I^{2}
$$

onde $\alpha$ e $\beta$ são, respectivamente, coeficientes indicativos da contribuição do arco e do efeito Joule para a fusão do eletrodo, s é o comprimento energizado do eletrodo e I é a corrente de soldagem. Starling e Modenesi[5-7] avaliaram a velocidade de fusão dos mesmos arames tubulares estudados no presente trabalho (utilizando uma fonte do tipo "tensão constante" e condições de soldagem essencialmente sem a ocorrência de curtos-circuitos) em função de diferentes parâmetros operacionais, como a corrente de soldagem, o gás de proteção e a polaridade do eletrodo. De uma forma geral, os autores verificaram que, nas mesmas condições operacionais avaliadas no presente trabalho, a Equação 2 também pode descrever satisfatoriamente a fusão de arames tubulares.

Através de um balanço térmico na ponta do eletrodo similar ao desenvolvido para arames maciços[23], Starling e Modenesi[3] propuseram um modelo para os coeficientes indicativos da contribuição do $\operatorname{arco}(\alpha)$ e do efeito Joule $(\beta)$ para a fusão dos arames tubulares rutílico, básico e "metal cored" estudados no presente trabalho. Segundo o modelo, os coeficientes $\alpha$ e $\beta$ dependem de propriedades tanto da fita metálica como do fluxo do arame, como densidade, área da seção transversal e quantidade de calor necessária para aquecer, fundir e vaporizar uma pequena parte do material. Os coeficientes $\alpha$ e $\beta$ também dependem, respectivamente, da contribuição do arco para o aquecimento do arame e da resistividade do arame. Assim, os coeficientes $\alpha$ e $\beta$ podem assumir diferentes valores dependendo das características particulares de cada arame tubular (por exemplo, geometria, composição química da fita e do fluxo) e também, em maior ou menor grau, das condições operacionais (por exemplo, composição do gás de proteção). Em relação às características dos arames tubulares avaliados no presente trabalho, Starling e Modenesi[3] verificaram, por exemplo, diferenças em suas características geométricas, densidades, resistividades elétricas e na composição química dos seus fluxos.

Dessa forma, para uma mesma velocidade de alimentação do arame (mantendo-se fixas as demais condições operacionais) é de se esperar que a soldagem com os diferentes arames tubulares avaliados resulte, por exemplo, em diferentes correntes de soldagem. Em função das variações na corrente média de soldagem, como o comprimento do arco foi mantido constante, também se espera variações na tensão média do arco. Da mesma forma, em função das diferentes composições químicas do fluxo, é possível que (para um mesmo gás de proteção) a soldagem com os diferentes arames tubulares avaliados resulte em alterações no arco elétrico (por exemplo, no potencial de ionização) e, assim, na tensão média do arco. Ainda, em função das diferentes resistividades dos arames tubulares, como o comprimento energizado do eletrodo foi mantido constante, é possível que (para um mesmo gás de proteção) haja uma tendência adicional de alteração na tensão média do arco. Nesse sentido, a análise dos resultados indica algumas tendências.

Observa-se que, para um mesmo gás de proteção e uma mesma velocidade de alimentação do arame, o valor médio da corrente é maior na soldagem com o arame "metal cored" e o 
valor da tensão média do arco é menor na soldagem com o arame rutílico. Entretanto, para uma mesma velocidade de alimentação do arame, a tensão média do arco é maior na soldagem com o arame "metal cored" (para proteção por $75 \% \mathrm{Ar}-25 \% \mathrm{CO}_{2}$ ) ou na soldagem com o arame básico (para proteção por $100 \% \mathrm{CO}_{2}$ ) e, ainda, o valor médio da corrente é menor na soldagem com o arame rutílico (para proteção por $100 \% \mathrm{CO}_{2}$ ).

\subsection{Avaliação Comparativa da Estabilidade Operacional}

Da mesma forma como observado por Starling e Modenesi[4] na soldagem em polaridade positiva, para uma mesma condição operacional (mesma velocidade de alimentação do arame e mesmo gás de proteção), a soldagem em polaridade negativa com os diferentes arames tubulares pode resultar em diferentes modos de transferência metálica e, assim, em diferenças na estabilidade operacional do processo. Nesse sentido, a análise

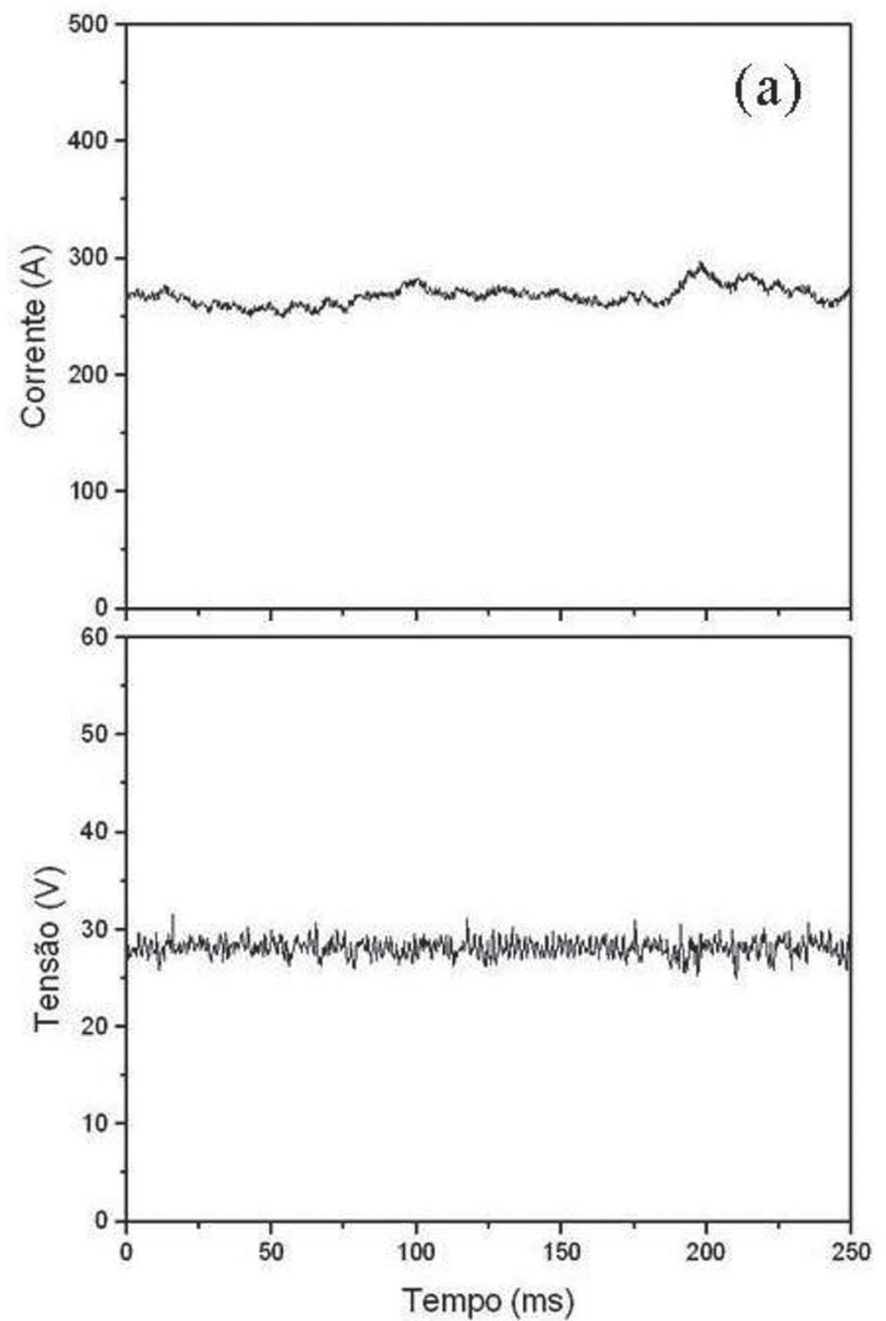

dos resultados indica algumas tendências.

Verifica-se que, para uma mesma velocidade de alimentação do arame, as menores flutuações na corrente de soldagem (menor relação entre o desvio padrão e a média deste parâmetro) ocorreram para o arame "metal cored" (para proteção pelos dois gases), indicando maiores estabilidades operacionais na soldagem com o mesmo, entretanto, as menores flutuações na tensão do arco ocorreram para o arame rutílico (com proteção por $100 \% \mathrm{CO}_{2}$ ) ou para o arame básico (com proteção por $75 \% \mathrm{Ar}-25 \% \mathrm{CO}_{2}$ ).

Para uma mesma velocidade de alimentação do arame, as maiores flutuações na corrente de soldagem ocorreram para o arame básico (para proteção por $100 \% \mathrm{CO}_{2}$ ) e as maiores flutuações na tensão do arco ocorreram para o arame rutílico (para proteção por $75 \% \mathrm{Ar}-25 \% \mathrm{CO}_{2}$ ), indicando menores estabilidades operacionais na soldagem com os mesmos.

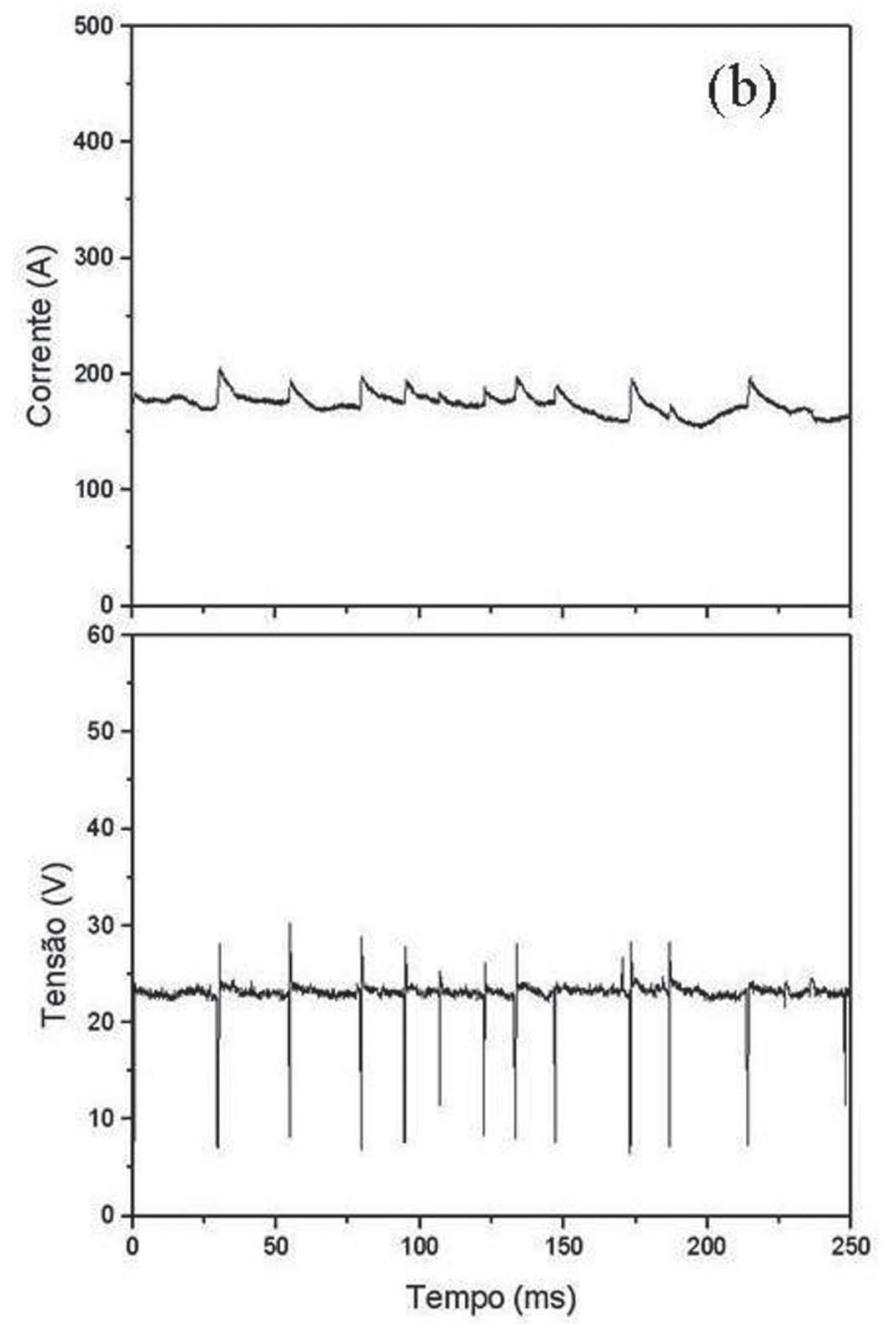

Figura 2. Exemplos de oscilogramas de corrente de soldagem e tensão do arco.

(a) "Metal cored", 75\% Ar- $25 \% \mathrm{CO}_{2}, \mathrm{w}=8,94 \pm 0,03 \mathrm{~m} / \mathrm{min}, \mathrm{I}=266 \pm 7 \mathrm{~A}(2,6 \%)$ e V = 28, $1 \pm 0,9 \mathrm{~V}(3,2 \%)$.

(b) Rutílico, $75 \% \mathrm{Ar}-25 \% \mathrm{CO}_{2}, \mathrm{w}=7,09 \pm 0,03 \mathrm{~m} / \mathrm{min}, \mathrm{I}=172 \pm 9 \mathrm{~A}(5,2 \%)$ e V = 23,0 $\pm 2,1 \mathrm{~V}(9,1 \%)$. 

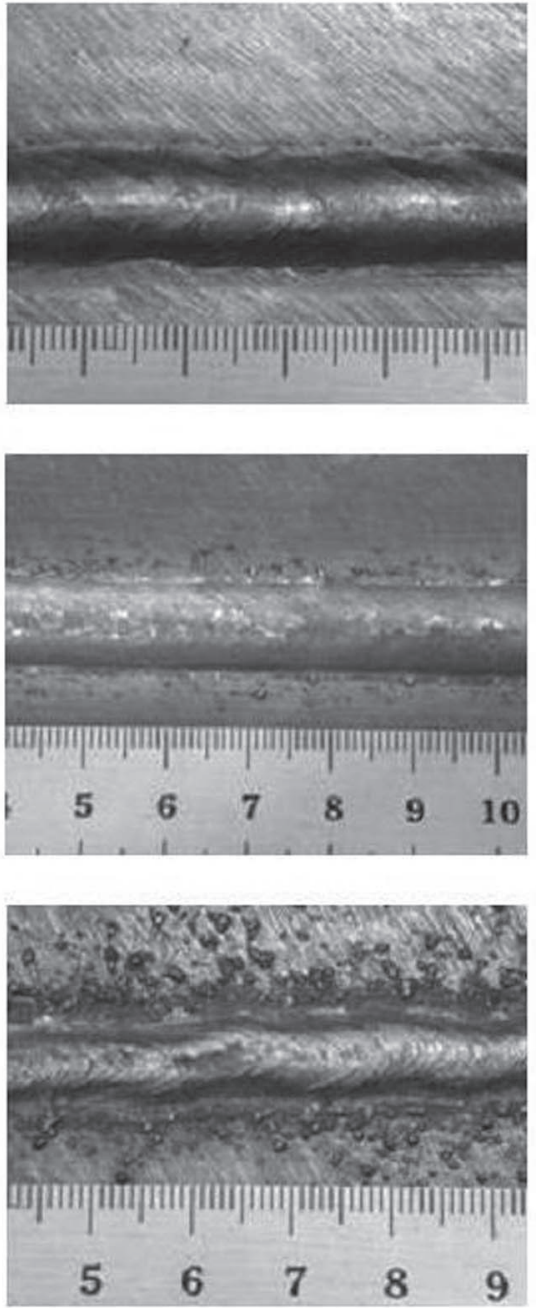

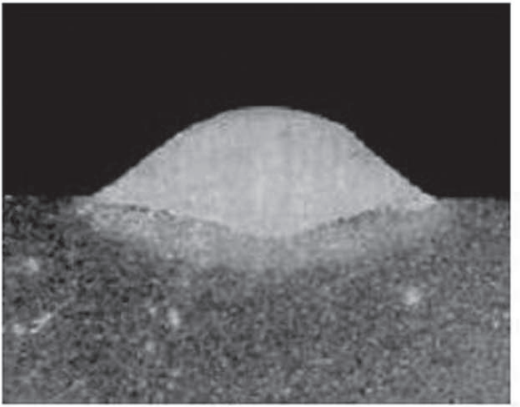

(a)

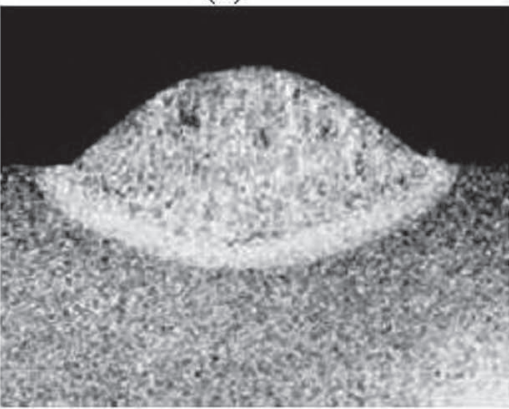

(b)

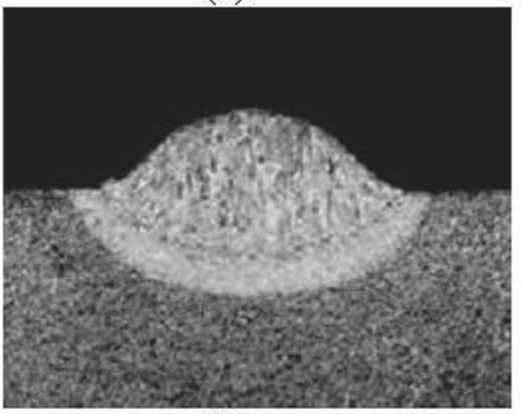

(c)
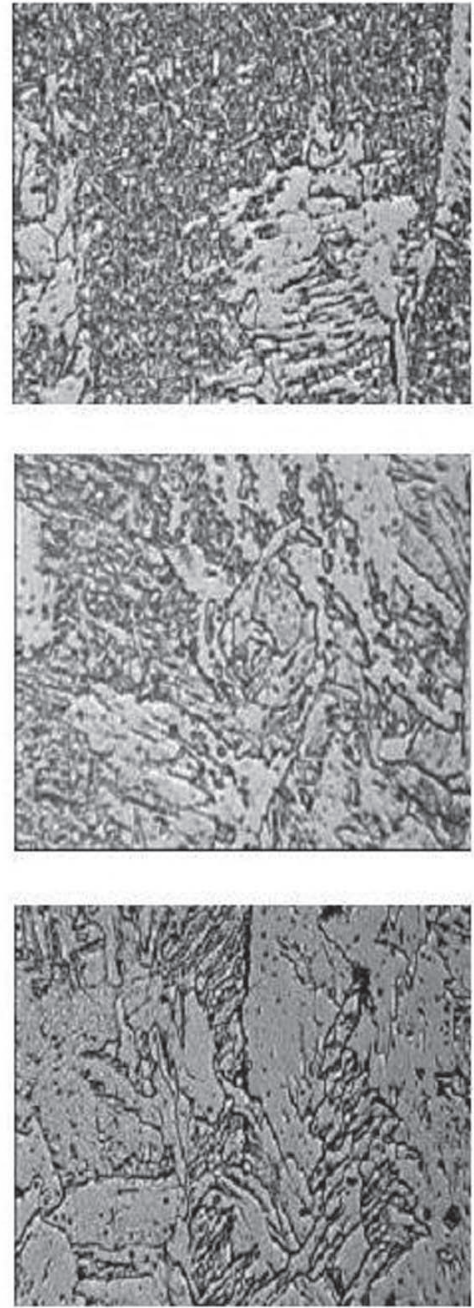

Figura 3. Exemplos de cordões obtidos para as soldas produzidas. Aspecto superficial (esquerda).

Macrografia - Nital $10 \%$ (centro). Micrografia - MO, 500 X, Nital $2 \%$ (direita).

(a) Básico, $75 \% \mathrm{Ar}-25 \% \mathrm{CO}_{2}$, velocidade de alimentação nominal de $9 \mathrm{~m} / \mathrm{min}$.

(b) "Metal cored", $75 \% \mathrm{Ar}-25 \% \mathrm{CO}_{2}$, velocidade de alimentação nominal de $9 \mathrm{~m} / \mathrm{min}$.

(c) Básico, $100 \% \mathrm{CO}_{2}$, velocidade de alimentação nominal de $7 \mathrm{~m} / \mathrm{min}$.

Tabela 2. Energia de soldagem $(H)$, eficiência de deposição $\left(\varphi_{\text {tubular }}\right)$ (média avaliada em pelo menos duas soldas), taxa de deposição $\left(\mathrm{TD}_{\text {tubular }}\right)$ e dureza Vickers $(\mathrm{HV})$ na zona fundida (intervalo de confiança: $95 \%$ ).

$\mathrm{w}$ - velocidade de alimentação nominal do arame.

\begin{tabular}{|c|c|c|c|c|c|c|}
\hline Arame Tubular & Gás Proteção & $\mathrm{w}(\mathrm{m} / \mathrm{min})$ & $\mathrm{H}(\mathrm{kJ} / \mathrm{mm})$ & $\varphi_{\text {tubular }}(\%)$ & $\mathrm{TD}_{\text {tubular }}(\mathrm{kg} / \mathrm{h})$ & $\mathrm{HV}(98,1 \mathrm{~N})$ \\
\hline \multirow{4}{*}{ Rutílico } & \multirow{2}{*}{$75 \% \mathrm{Ar}-25 \% \mathrm{CO}_{2}$} & 7 & 0,84 & 84 & 2,44 & $259 \pm 16$ \\
\hline & & 9 & 0,84 & 87 & 3,25 & $235 \pm 9$ \\
\hline & \multirow{2}{*}{$100 \% \mathrm{CO}_{2}$} & 7 & 1,11 & 72 & 2,09 & $179 \pm 4$ \\
\hline & & 9 & 1,12 & 64 & 2,39 & $182 \pm 5$ \\
\hline \multirow{4}{*}{ Básico } & \multirow{2}{*}{$75 \% \mathrm{Ar}-25 \% \mathrm{CO}_{2}$} & 7 & 0,90 & 91 & 2,66 & $227 \pm 8$ \\
\hline & & 9 & 0,97 & 90 & 3,38 & $207 \pm 6$ \\
\hline & \multirow{2}{*}{$100 \% \mathrm{CO}_{2}$} & 7 & 1,33 & 69 & 2,02 & $150 \pm 7$ \\
\hline & & 9 & 1,43 & 67 & 2,52 & $163 \pm 2$ \\
\hline \multirow{4}{*}{$\begin{array}{l}\text { "Metal } \\
\text { Cored" }\end{array}$} & \multirow{2}{*}{$75 \% \mathrm{Ar}-25 \% \mathrm{CO}_{2}$} & 7 & 1,27 & 89 & 3,01 & $174 \pm 3$ \\
\hline & & 9 & 1,25 & 97 & 4,22 & $167 \pm 3$ \\
\hline & \multirow{2}{*}{$100 \% \mathrm{CO}_{2}$} & 7 & 1,59 & 62 & 2,10 & $124 \pm 2$ \\
\hline & & 9 & 1,61 & 59 & 2,57 & $128 \pm 3$ \\
\hline
\end{tabular}


Tabela 3. Parâmetros obtidos para os cordões de solda (média dos valores avaliados em duas macrografias). W - velocidade de alimentação nominal do arame, $\mathrm{W}$ - largura, $\mathrm{h}$ - reforço, $\mathrm{P}_{\max }$ - penetração máxima, $\mathrm{A}_{\mathrm{d}}$ - área depositada, $\mathrm{A}_{\mathrm{p}}$ - área de penetração e $\delta$ - diluição.

\begin{tabular}{|c|c|c|c|c|c|c|c|c|}
\hline Arame Tubular & Gás Proteção & $\begin{array}{c}\mathrm{W} \\
(\mathrm{m} / \mathrm{min})\end{array}$ & $\begin{array}{c}\mathrm{W} \\
(\mathrm{mm})\end{array}$ & $\begin{array}{c}\mathrm{h} \\
(\mathrm{mm})\end{array}$ & $\underset{(\mathrm{mm})}{\mathrm{P}_{\max }}$ & $\underset{\left(\mathrm{mm}^{2}\right)}{\mathrm{A}_{\mathrm{d}}}$ & $\underset{\left(\mathrm{mm}^{2}\right)}{\mathrm{A}_{\mathrm{p}}}$ & $\begin{array}{c}\delta \\
(\%)\end{array}$ \\
\hline \multirow{4}{*}{ Rutílico } & \multirow{2}{*}{$75 \% \mathrm{Ar}-25 \% \mathrm{CO}_{2}$} & 7 & 9,3 & 2,7 & 0,6 & 18,0 & 3,5 & 16,4 \\
\hline & & 9 & 10,1 & 2,9 & 1,0 & 20,2 & 4,6 & 18,6 \\
\hline & \multirow{2}{*}{$100 \% \mathrm{CO}_{2}$} & 7 & 11,3 & 2,4 & 1,6 & 16,3 & 12,1 & 42,5 \\
\hline & & 9 & 12,1 & 2,4 & 1,7 & 16,5 & 16,7 & 50,2 \\
\hline \multirow{4}{*}{ Básico } & \multirow{2}{*}{$75 \% \mathrm{Ar}-25 \% \mathrm{CO}_{2}$} & 7 & 10,6 & 3,1 & 1,0 & 21,0 & 6,0 & 22,3 \\
\hline & & 9 & 11,7 & 3,0 & 1,3 & 20,4 & 9,0 & 30,5 \\
\hline & \multirow{2}{*}{$100 \% \mathrm{CO}_{2}$} & 7 & 10,4 & 2,8 & 2,6 & 16,4 & 15,7 & 48,9 \\
\hline & & 9 & 10,8 & 2,2 & 2,9 & 13,5 & 23,1 & 63,1 \\
\hline \multirow{4}{*}{$\begin{array}{l}\text { "Metal } \\
\text { Cored" }\end{array}$} & \multirow{2}{*}{$75 \% \mathrm{Ar}-25 \% \mathrm{CO}_{2}$} & 7 & 11,8 & 3,0 & 1,5 & 22,5 & 12,5 & 35,7 \\
\hline & & 9 & 12,3 & 3,3 & 2,5 & 24,6 & 17,7 & 41,8 \\
\hline & \multirow{2}{*}{$100 \% \mathrm{CO}_{2}$} & 7 & 16,0 & 1,8 & 2,8 & 16,3 & 32,1 & 66,3 \\
\hline & & 9 & 13,9 & 2,1 & 3,4 & 17,7 & 33,4 & 65,4 \\
\hline
\end{tabular}

Tabela 4. Fração volumétrica dos microconstituintes presentes na zona fundida. Intervalo de confiança: $95 \%$.

\begin{tabular}{|c|c|c|c|c|c|c|c|}
\hline $\begin{array}{l}\text { Arame } \\
\text { Tubular }\end{array}$ & $\begin{array}{c}\text { Gás } \\
\text { Proteção }\end{array}$ & $\begin{array}{c}\mathrm{w} \\
(\mathrm{m} / \mathrm{min})\end{array}$ & $\begin{array}{c}\mathrm{PF}(\mathrm{G}) \\
(\%)\end{array}$ & $\begin{array}{c}\mathrm{PF}(\mathrm{I}) \\
(\%)\end{array}$ & $\begin{array}{l}\mathrm{AF} \\
(\%)\end{array}$ & $\begin{array}{c}\text { FS(NA) } \\
(\%)\end{array}$ & $\begin{array}{c}\mathrm{FS}(\mathrm{A}) \\
(\%)\end{array}$ \\
\hline \multirow{4}{*}{ Rutílico } & \multirow{2}{*}{$75 \% \mathrm{Ar}-25 \% \mathrm{CO}_{2}$} & 7 & $2,2 \pm 0,6$ & $0,2 \pm 0,2$ & $32,8 \pm 2,3$ & $58,0 \pm 2,5$ & $6,9 \pm 1,2$ \\
\hline & & 9 & $4,5 \pm 1,0$ & $0,1 \pm 0,1$ & $27,6 \pm 2,3$ & $61,5 \pm 2,6$ & $6,7 \pm 1,2$ \\
\hline & \multirow{2}{*}{$100 \% \mathrm{CO}_{2}$} & 7 & $26,7 \pm 2,6$ & $6,7 \pm 1,2$ & $28,6 \pm 2,6$ & $24,8 \pm 2,7$ & $13,2 \pm 1,9$ \\
\hline & & 9 & $25,3 \pm 2,3$ & $6,5 \pm 1,1$ & $30,0 \pm 2,9$ & $23,5 \pm 2,3$ & $14,6 \pm 2,1$ \\
\hline \multirow{4}{*}{ Básico } & \multirow{2}{*}{$75 \% \mathrm{Ar}-25 \% \mathrm{CO}_{2}$} & 7 & $12,7 \pm 1,7$ & $2,6 \pm 0,7$ & $27,6 \pm 1,9$ & $48,6 \pm 2,5$ & $8,5 \pm 1,4$ \\
\hline & & 9 & $14,5 \pm 2,2$ & $1,8 \pm 0,7$ & $25,9 \pm 2,3$ & $50,6 \pm 2,8$ & $7,2 \pm 1,1$ \\
\hline & \multirow{2}{*}{$100 \% \mathrm{CO}_{2}$} & 7 & $20,9 \pm 2,6$ & $5,1 \pm 1,1$ & $13,5 \pm 2,2$ & $40,4 \pm 2,8$ & $20,2 \pm 2,7$ \\
\hline & & 9 & $20,7 \pm 2,7$ & $3,9 \pm 1,0$ & $12,6 \pm 2,0$ & $41,3 \pm 3,1$ & $21,5 \pm 2,7$ \\
\hline \multirow{4}{*}{$\begin{array}{l}\text { "Metal } \\
\text { Cored" }\end{array}$} & \multirow{2}{*}{$75 \% \mathrm{Ar}-25 \% \mathrm{CO}_{2}$} & 7 & $18,0 \pm 1,8$ & $4,5 \pm 1,1$ & $28,6 \pm 3,5$ & $37,7 \pm 3,1$ & $11,2 \pm 1,9$ \\
\hline & & 9 & $16,5 \pm 2,0$ & $5,0 \pm 1,1$ & $33,1 \pm 3,5$ & $33,8 \pm 3,4$ & $11,6 \pm 1,9$ \\
\hline & \multirow{2}{*}{$100 \% \mathrm{CO}_{2}$} & 7 & $12,6 \pm 1,5$ & $10,5 \pm 1,7$ & $9,6 \pm 1,4$ & $48,1 \pm 2,2$ & $19,2 \pm 2,4$ \\
\hline & & 9 & $15,4 \pm 1,8$ & $12,1 \pm 1,9$ & $7,7 \pm 1,6$ & $47,5 \pm 2,4$ & $17,3 \pm 2,5$ \\
\hline
\end{tabular}

$\mathrm{PF}(\mathrm{G})$ - ferrita primária de contorno de grão; $\mathrm{PF}(\mathrm{I})$ - ferrita primária intragranular; AF - ferrita acicular; FS(NA) e FS(A) - ferritas com segunda fase não alinhada e alinhada. w - velocidade de alimentação nominal.

De acordo com a Tabela 2, nota-se que, para uma mesma velocidade de alimentação do arame, as menores eficiências de deposição ocorreram para o arame rutílico (na soldagem com $75 \% \mathrm{Ar}-25 \% \mathrm{CO}_{2}$ ) ou para o arame "metal cored" (na soldagem com $100 \% \mathrm{CO}_{2}$ ), indicando as menores estabilidades operacionais na soldagem com os mesmos. Estes resultados representam uma aparente dualidade considerando, conforme descrito acima, que as menores flutuações na corrente de soldagem ocorreram para o arame "metal cored" na soldagem com os dois gases. Isto decorre de que, apesar da eficiência de deposição estar associada com os níveis de flutuação dos valores da corrente de soldagem, a mesma também deve depender de outros fatores. Assim, a estabilidade operacional quando avaliada por diferentes parâmetros complementares não necessariamente resulta em tendências equivalentes.
Na soldagem com $75 \%$ Ar- $25 \% \mathrm{CO}_{2}$ (para as duas velocidades de alimentação do arame) os cordões isentos de respingos e com boa regularidade superficial ocorreram para o arame básico, indicando maiores estabilidades operacionais. Na soldagem com $100 \% \mathrm{CO}_{2}$ (para as duas velocidades de alimentação do arame), os cordões com os menores níveis de respingos e mais regulares superficialmente ocorreram para o arame rutílico, indicando maiores estabilidades operacionais.

Em função das diferenças relatadas na eficiência de deposição, Tabela 2, e, segundo Starling e Modenesi[3], das diferenças na área da seção transversal e na densidade volumétrica dos arames, de acordo com a Equação 2, é de se esperar diferenças nos valores de taxa de deposição resultantes da soldagem com diferentes arames tubulares para uma mesma velocidade de alimentação do arame. De acordo com a Tabela 
2, para um mesmo gás de proteção e uma mesma velocidade de alimentação do arame, os maiores valores de taxa de deposição ocorreram para o arame "metal cored". Ainda segundo a Tabela 2, na soldagem com $75 \% \mathrm{Ar}-25 \% \mathrm{CO}_{2}$ para uma mesma velocidade de alimentação do arame, os menores valores de taxa de deposição ocorreram para o arame rutílico.

\subsection{Avaliação Comparativa da Geometria, Microestrutura e Dureza do Cordão}

Em função das variações relatadas na corrente média de soldagem e na tensão média do arco resultantes da soldagem com diferentes arames tubulares para uma mesma condição operacional, é de se esperar variações na energia de soldagem. De acordo com a Tabela 2, verifica-se que, para um mesmo gás de proteção e uma mesma velocidade de alimentação do arame, os maiores valores da energia de soldagem ocorreram para o arame "metal cored", enquanto os menores valores de energia de soldagem ocorreram para o arame rutílico. Assim, essas variações na energia de soldagem podem resultar em variações na geometria do cordão de solda e na diluição. Adicionalmente, mesmo com a manutenção das velocidades de soldagem e de alimentação do arame, a soldagem com diferentes arames tubulares (para um gás de proteção) também pode resultar em variações na área depositada em função das variações relatadas na eficiência de deposição, Tabela 2. Nesse sentido, a análise dos resultados indica algumas tendências.

A Tabela 3 indica que na soldagem com $75 \%$ Ar- $25 \% \mathrm{CO}_{2}$ (para as duas velocidades de alimentação do arame) os maiores valores de largura, penetração máxima, área depositada, área de penetração e diluição ocorreram para o arame "metal cored". Nessas condições, os menores valores de largura, reforço, penetração máxima, área depositada, área de penetração e diluição ocorreram para o arame rutílico. $\mathrm{Na}$ soldagem com $100 \% \mathrm{CO}_{2}$ (para as duas velocidades de alimentação do arame) os maiores valores de largura, penetração máxima, área de penetração e diluição ocorreram para o arame "metal cored". Nessas condições, os menores valores de largura e reforço ocorreram, respectivamente, para os arames básico e "metal cored", enquanto os menores valores de penetração máxima, área de penetração e diluição ocorreram para o arame rutílico.

Em função das diferenças na composição química dos fluxos dos arames tubulares avaliados no presente trabalho relatadas por Starling e Modenesi[3], é de se esperar que, para um mesmo gás de proteção e uma mesma velocidade de alimentação do arame, ocorram variações na composição química da zona fundida devido à variações nos níveis de elementos de liga fornecidos à poça de fusão e/ou perdidos por oxidação. Ainda, as variações relatadas na diluição, Tabela 3, e na energia de soldagem, Tabela 2, observadas na soldagem com diferentes arames tubulares (para um mesmo gás e proteção e uma mesma velocidade de alimentação do arame) também podem contribuir para variações na composição química da zona fundida e na velocidade de resfriamento das soldas. Dessa forma, para uma mesma velocidade de alimentação do arame e um mesmo gás de proteção, a soldagem com os diferentes arames tubulares pode resultar em diferentes microestruturas e durezas na zona fundida, considerando que os aspectos acima relacionados afetam a composição química e a velocidade de resfriamento das soldas. Nesse sentido, a análise dos resultados indica algumas tendências.

Observando-se os resultados da metalografia quantitativa apresentados na Tabela 4, percebe-se que na soldagem com $75 \% \mathrm{Ar}-25 \% \mathrm{CO}_{2}$ (para as duas velocidades de alimentação do arame) as maiores frações de ferrita primária intragranular (PF(I)) e de ferrita com segunda não alinhada (FS(NA)) ocorreram, respectivamente, para os arames "metal cored" e rutílico. Nessas condições, as menores frações de ferrita primária de contorno de grão $((\mathrm{PF}(\mathrm{G}))$ e de ferrita primária intragranular $(\mathrm{PF}(\mathrm{I}))$ ocorreram para o arame rutílico, enquanto as menores frações de ferrita com segunda fase não alinhada (FS(NA) ocorreram para o arame "metal cored". Na soldagem com $100 \% \mathrm{CO}_{2}$ (para as duas velocidades de alimentação do arame), as maiores frações de ferrita primária intragranular $(\mathrm{PF}(\mathrm{I}))$ e ferrita com segunda fase não alinhada (FS(NA)) ocorreram para o arame "metal cored", enquanto as maiores frações de ferrita acicular (AF) ocorreram para o rutílico. Nessas condições, as menores frações de ferrita primária de contorno de grão $(\mathrm{PF}(\mathrm{G}))$ e de ferrita acicular (AF) ocorreram para o arame "metal cored", enquanto as menores frações de ferrita com segunda não alinhada (FS(NA)) ocorreram para o arame rutílico. Nota-se também que (para os dois gases de proteção e para as duas velocidades de alimentação do arame), a zona fundida com microestrutura mais grosseira ocorre para o arame "metal cored", enquanto aquelas resultantes dos arames rutílico e básico são igualmente refinadas. De acordo com a Tabela 2, para um mesmo gás de proteção e uma mesma velocidade de alimentação do arame, os maiores valores de dureza ocorreram para o arame rutílico, enquanto que os menores valores ocorreram para o arame "metal cored".

\subsection{Condições Operacionais Otimizadas}

Em princípio, desejam-se na soldagem de chapas grossas de aços estruturais com os arames tubulares condições de boa estabilidade operacional e de maior taxa de deposição. É desejável que essas condições sejam associadas a um cordão com boa aparência superficial, boa penetração e ausência de descontinuidades. Também se almeja uma microestrutura com predominância de microconstituintes capazes de favorecer a resistência mecânica, aliada a uma boa tenacidade e ductilidade da solda (por exemplo, com teores mais altos de ferrita acicular e mais baixos de ferrita primária de contorno de grão).

Percebe-se que todas as condições operacionais avaliadas com os arames tubulares rutílico, básico e "metal cored" resultaram em cordões com aparentemente os mesmos níveis de porosidades e inclusões de escória e sem a presença de mordeduras. De acordo com a Tabela 2, para uma mesma velocidade de alimentação do arame, os maiores valores de taxa de deposição ocorreram para o arame "metal cored" (principalmente na soldagem com $75 \% \mathrm{Ar}-25 \% \mathrm{CO}_{2}$ ). As melhores estabilidades operacionais e que também resultaram em cordões com boa aparência superficial e com isenção de respingos ocorreram para o arame básico 
na soldagem com $75 \%$ Ar- $25 \% \mathrm{CO}_{2}$. De acordo com a Tabela 2, para uma mesma velocidade de alimentação do arame, as microestruturas da zona fundida com maior dureza (capazes de favorecer a resistência mecânica) ocorreram para o arame rutílico, seguido pelo arame básico (em ambos, principalmente na soldagem com $75 \% \mathrm{Ar}-25 \% \mathrm{CO}_{2}$ ). De acordo com a Tabela 4 , os maiores teores de ferrita acicular associados aos menores teores de ferrita primária de contorno de grão (capazes de favorecer a tenacidade da zona fundida) ocorreram para o arame rutílico na soldagem com $75 \% \mathrm{Ar}-25 \% \mathrm{CO}_{2}$. Entretanto, de acordo com a Tabela 3 , as maiores penetrações tenderam a ocorrer para o arame "metal cored", seguido pelo arame básico (em ambos, principalmente na soldagem com $100 \% \mathrm{CO}_{2}$ ).

Assim, para uma mesma velocidade de alimentação do arame, caso uma alta taxa de deposição, associada a uma boa penetração sejam os requisitos principais, as condições operacionais mais adequadas envolveriam a utilização do arame "metal cored" na soldagem com $75 \% \mathrm{Ar}-25 \% \mathrm{CO}_{2}$. A Figura 2(b) ilustra o cordão resultante para a velocidade de alimentação do arame de $9 \mathrm{~m} / \mathrm{min}$.

Para uma mesma velocidade de alimentação do arame, caso as propriedades mecânicas adequadas da zona fundida (altas resistência mecânica e tenacidade) sejam os requisitos principais, as condições operacionais mais adequadas envolveriam a utilização do arame "rutílico" na soldagem com $75 \% \mathrm{Ar}-25 \% \mathrm{CO}_{2}$.

Alternativamente, para uma mesma velocidade de alimentação do arame, uma boa aparência superficial do cordão, associada a uma isenção de respingos e a valores intermediários de propriedades mecânicas e penetração, podem ser obtidos com a utilização do arame básico na soldagem com $75 \% \mathrm{Ar}-25 \% \mathrm{CO}_{2}$. A Figura 2(a) ilustra o cordão resultante para a velocidade de alimentação do arame de $9 \mathrm{~m} / \mathrm{min}$.

\section{Conclusões}

No presente trabalho, realizou-se um estudo comparativo das características operacionais do processo e do cordão resultantes da utilização de arames tubulares dos tipos rutílico, básico e "metal cored" na soldagem sobre chapa grossa de um aço carbono comum de baixo carbono com polaridade negativa e em posição plana, variando-se o tipo de gás de proteção (75\%Ar$25 \% \mathrm{CO}_{2}$ e $100 \% \mathrm{CO}_{2}$ ) e a velocidade de alimentação do arame (7 e $9 \mathrm{~m} / \mathrm{min}$ ). Para tanto, avaliaram-se a microestrutura (através de metalografia quantitativa), geometria, dureza, nível de respingos e aspecto superficial dos cordões e, adicionalmente, os oscilogramas de corrente de soldagem e tensão do arco e os valores de taxa deposição. Verificou-se que, para uma mesma velocidade de alimentação do arame:

- Na soldagem com $75 \% \mathrm{Ar}-25 \% \mathrm{CO}_{2}$, os cordões isentos de respingos e com boa regularidade superficial ocorreram para o arame básico. Na soldagem com $100 \% \mathrm{CO}_{2}$, os cordões com os menores níveis de respingos e mais regulares superficialmente ocorreram para o arame rutílico.

- Os maiores valores de taxa de deposição ocorreram para o arame "metal cored". Na soldagem com $75 \% \mathrm{Ar}-25 \% \mathrm{CO}_{2}$, os menores valores de taxa de deposição ocorreram para o arame rutílico.

- $\mathrm{Na}$ soldagem com $75 \% \mathrm{Ar}-25 \% \mathrm{CO}_{2}$, os maiores valores de largura, penetração máxima, área depositada, área de penetração e diluição ocorreram para o arame "metal cored". Nessa condição, os menores valores de largura, reforço, penetração máxima, área depositada, área de penetração e diluição ocorreram para o arame rutílico.

- Na soldagem com $100 \% \mathrm{CO}_{2}$, os maiores valores de largura, penetração máxima, área de penetração e diluição ocorreram para o arame "metal cored". Nessa condição, os menores valores de largura e reforço ocorreram, respectivamente, para os arames básico e "metal cored", enquanto os menores valores de penetração máxima, área de penetração e diluição ocorreram para o arame rutílico.

- $\mathrm{Na}$ soldagem com $75 \% \mathrm{Ar}-25 \% \mathrm{CO}_{2}$, as maiores frações de ferrita primária intragranular e de ferrita com segunda não alinhada ocorreram, respectivamente, para os arames "metal cored" e rutílico. Nessa condição, as menores frações de ferrita primária de contorno de grão e de ferrita primária intragranular ocorreram para o arame rutílico, enquanto as menores frações de ferrita com segunda fase não alinhada ocorreram para o arame "metal cored".

- Na soldagem com $100 \% \mathrm{CO}_{2}$, as maiores frações de ferrita primária intragranular e ferrita com segunda fase não alinhada ocorreram para o arame "metal cored", enquanto as maiores frações de ferrita acicular ocorreram para o rutílico. Nessa condição, as menores frações de ferrita primária de contorno de grão e de ferrita acicular ocorreram para o arame "metal cored", enquanto as menores frações de ferrita com segunda não alinhada ocorreram para o arame rutílico.

- Os maiores valores de dureza ocorreram para o arame rutílico, enquanto que os menores valores ocorreram para o arame "metal cored".

- Caso uma alta taxa de deposição associada a uma boa penetração sejam os requisitos principais, as condições operacionais mais adequadas envolveriam a utilização do arame "metal cored" na soldagem com $75 \% \mathrm{Ar}-25 \% \mathrm{CO}_{2}$.

- Caso as propriedades mecânicas adequadas da zona fundida (altas resistência mecânica e tenacidade) sejam os requisitos principais, as condições operacionais mais adequadas envolveriam a utilização do arame rutílico na soldagem com $75 \% \mathrm{Ar}-25 \% \mathrm{CO}_{2}$.

- Uma boa aparência superficial do cordão, associada a uma isenção de respingos e a valores intermediários de propriedades mecânicas e penetração pode ser obtida com a utilização do

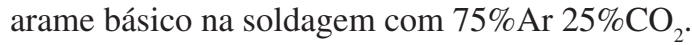

\section{Agradecimentos}

Os autores agradecem a todos que contribuíram para a realização deste trabalho. Em particular à FAPEMIG pelo apoio financeiro, representado por concessão de bolsa de iniciação científica e pela contratação do Projeto de Pesquisa TEC 423/06. 


\section{Referências Bibliográficas}

[1] MARQUES, P.V.; MODENESI, P.J.; BRACARENSE, A.Q. Soldagem Mig/Mag e com Arame Tubular. In: MARQUES, P.V.; MODENESI, P.J.; BRACARENSE, A.Q. Soldagem: Fundamentos e Tecnologia. 1a. ed., Belo Horizonte: UFMG, 2005. p.233-261.

[2] AMERICAN WELDING SOCIETY. Welding Process. In: AMERICAN WELDING SOCIETY. Welding Handbook, v.2, $8^{\text {th }}$ ed., Miami: AWS, 1991. p.158-190.

[3] STARLING, C.M.D.; MODENESI, P.J. Proposed Model for the Fusion of Tubular Wires, Welding International, London, v.22, p.817-825, 2008.

[4] STARLING, C.M.D.; MODENESI, P.J. Metal Transfer Evaluation of Tubular Wires, Welding International, London, v.21, p.412-420, 2007.

[5] STARLING, C.M.D.; MODENESI, P.J. Avaliação da Velocidade de Fusão do Arame na Soldagem FCAW com Eletrodo Negativo, Soldagem \& Inspeção, São Paulo, v.10, n.1, p.31-37, 2005.

[6] STARLING, C.M.D.; MODENESI, P.J. Efeito da Polaridade do Eletrodo na Velocidade de Fusão de Arames Tubulares, Soldagem \& Inspeção, São Paulo, v.10, n.3, p.101-108, 2005.

[7] STARLING, C.M.D. et al. Avaliação da Velocidade de Fusão de Arames Tubulares, Soldagem \& Inspeção, São Paulo, v.9, n.1, p.31-37, 2004.

[8] OLIVEIRA, J.E.M.; BRACARENSE, A.Q. Estudo da Morfologia do Cordão de Solda Obtido com o Processo Arame Tubular em Diferentes Posições de Soldagem. In: CONGRESSO NACIONAL DE SOLDAGEM, 29, 2003, São Paulo. Anais... São Paulo: Associação Brasileira de Soldagem, 2003, 12p.

[9] ARAÚJO, W.R. Comparação entre a Soldagem Robotizada com Arame Sólido e "Metal Cored" - A ocorrência do "Finger": 2004. 79p. Dissertação (Mestrado) - Curso de Pós-Graduação em Eng. Mecânica, Escola de Engenharia da Universidade Federal de Minas Gerais, Belo Horizonte.

[10] BRAGA, E.M.; MOTA, C.A.M.; FARIAS, J.P. Uma Contribuição ao Estudo da Soldagem a Arame Tubular Autoprotegido em Corrente Pulsada. In: ENCONTRO NACIONAL DE TECNOLOGIA DA SOLDAGEM, 24, 1998, Fortaleza. Anais... São Paulo: Associação Brasileira de Soldagem, 1998. 10p.

[11] BLACKMAN, S. et al. Pulsed MIG Welding with GásShielded Flux Cored Wires - MIG Synergic Update, Welding \& Metal Fabrication - Special Supplement, p.12-14, april 1998. [12] SVOBODA, H. et al. Efecto de los Parámetros de Soldadura sobre las Propiedades de los Depósitos Ferríticos Aleados al C-Mn-Ni Obtenidos con Alambres Tubulares de Relleno Rutílico y Metálico. In: CONGRESSO NACIONAL DE SOLDAGEM, 29, 2003, São Paulo. Anais... São Paulo: Associação Brasileira de Soldagem, 2003. 12p.

[13] VENTRELLA, V.A. Microestrutura e Tenacidade do Aço API 5LX - Grau 70 Soldado com Arame Tubular AWS E-81T1Ni1 e Eletrodo Revestido AWS E-8010-G. In: CONGRESSO BRASILEIRO DE ENGENHARIA E CIÊNCIA DOS MATERIAIS, 26, 2004, Porto Alegre. Anais... Porto Alegre: Associação Brasileira de Ciências Mecânicas, 2004. 15p.
[14] SANTOS NETO, N.F.; TREVISAN, R.E. Caracterização de Juntas de Aço API 5L X-70 Soldadas pelo Processo de Soldagem a Arco com Arame Tubular Autoprotegido. In: CONGRESSO NACIONAL DE SOLDAGEM, 30, 2004, Rio de Janeiro. Anais... São Paulo: Associação Brasileira de Soldagem, 2004. 8p.

[15] FALS, H.C.; TREVISAN, R.E. Características do Trincamento Assistido pelo Hidrogênio de um Aço Microligado Soldado pelo Processo FCAW. In: ENCONTRO NACIONAL DE TECNOLOGIA DA SOLDAGEM, 24, 1998, Fortaleza. Anais... São Paulo: Associação Brasileira de Soldagem, 1998. $10 \mathrm{p}$.

[16] STARLING, C.M.D.; MODENESI, P.J.; BORBA, T.M.D. Bead Characterization on FCAW Welding of a Basic Tubular Wire, Welding International, London, v.24, p.485-498, 2010.

[17] STARLING, C.M.D.; MODENESI, P.J.; BORBA, T.M.D. Bead Characterization of FCAW of a Rutilic Fluxed Core Wire, Welding International, London, v.25, p.825-837, 2011.

[18] STARLING, C.M.D.; MODENESI, P.J.; BORBA, T.M.D. Caracterização do Cordão na Soldagem FCAW com um Arame Tubular "Metal Cored", Soldagem \& Inspeção, São Paulo, v.16, p.285-300, 2011.

[19] STARLING, C.M.D.; MODENESI, P.J.; BORBA, T.M.D. Comparison of Operational Performance and Bead Characteristics when Welding with Different Tubular Wires, Welding International, London, v.24, p.579-592, 2010.

[20] INTERNATIONAL INSTITUTE OF WELDING. IIW Doc. n. IX-1533-88; Guide to the Light Microscope Examination of Ferritic Steel Weld Metals. 1988. 20p.

[21] AMERICAN SOCIETY FOR TESTING AND MATERIALS, Philadelphia. ASTM E562-89; Standard Test Method for Determining Volume Fraction by Systematic Manual Point Count. Philadelphia, 1989. Annual Book of ASTM Standards, p. 502-507.

[22] LESNEWICH, A. Control of Melting Rate ands Metal Transfer - Part I, Welding Journal, Miami, n.8, p.343s-353s, 1958.

[23] LANCASTER, J.F. The Physics of Welding. 2.ed. Pergamon Press \& International Institute of Welding, 1986. 340p. 